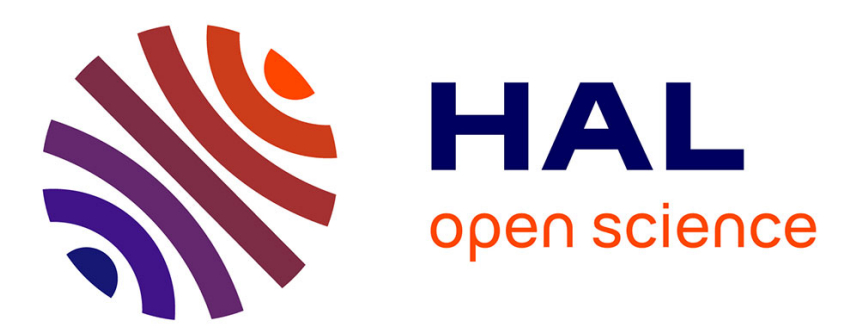

\title{
A mathematical model for VOCs removal in a treatment process coupling absorption and biodegradation
}

\author{
E. Wantz, A. Kane, M. Lhuissier, Abdeltif Amrane, Jean-Luc Audic, \\ Annabelle Couvert
}

\section{- To cite this version:}

E. Wantz, A. Kane, M. Lhuissier, Abdeltif Amrane, Jean-Luc Audic, et al.. A mathematical model for VOCs removal in a treatment process coupling absorption and biodegradation. Chemical Engineering Journal, 2021, 423, pp.130106. 10.1016/j.cej.2021.130106 . hal-03249764

\section{HAL Id: hal-03249764 https://hal.science/hal-03249764}

Submitted on 14 Jun 2021

HAL is a multi-disciplinary open access archive for the deposit and dissemination of scientific research documents, whether they are published or not. The documents may come from teaching and research institutions in France or abroad, or from public or private research centers.
L'archive ouverte pluridisciplinaire HAL, est destinée au dépôt et à la diffusion de documents scientifiques de niveau recherche, publiés ou non, émanant des établissements d'enseignement et de recherche français ou étrangers, des laboratoires publics ou privés. 
A mathematical model for VOCs removal in a treatment process coupling absorption and biodegradation

Eliot Wantza ${ }^{a}$ Abdoulaye Kane ${ }^{b}$, Margaux Lhuissiera ${ }^{a}$ Abdeltif Amranea ${ }^{\text {, Jean-Luc Audic }}{ }^{a}$, Annabelle Couvert $^{\mathrm{a}}$

aUniv Rennes, Ecole Nationale Supérieure de Chimie de Rennes, CNRS, ISCR - UMR 6226, F-35000

Rennes, France

bUniLaSalle-Ecole des Métiers de l'Environnement, Campus de Ker Lann, 35170 Bruz, France

\begin{tabular}{|c|c|}
\hline ETOAc & Ethyl Acetate \\
\hline G & Refer to gas phase \\
\hline GC-FID & Gas Chromatography with Flame Ionization Detector \\
\hline in & Bioreactor input \\
\hline IPA & Isopropanol \\
\hline$L$ & Refer to liquid phase \\
\hline $\mathrm{m}$ & mass \\
\hline MIBK & Methyl Isobutyl Ketone \\
\hline NAPL & Non-Aqueous Phase Liquid \\
\hline PDMS & Polydimethylsiloxane \\
\hline out & Bioreactor output \\
\hline RSD & Relative Standard Deviation \\
\hline TGA & Thermo Gravimetric Analysis \\
\hline TMB & Mesitylene or 1,3,5-trimethylbenzene \\
\hline TPPB & Two-Phase Partitioning Bioreactor \\
\hline VOC & Volatile Organic Compounds \\
\hline
\end{tabular}


W

Refer to aqueous phase

Nomenclature

C VOC concentration $\left(\mathrm{g} \cdot \mathrm{m}^{-3}\right)$

$D_{i, j} \quad$ Diffusion coefficient of component $\mathrm{i}(\mathrm{VOC})$ in phase $\mathrm{j}\left(\mathrm{m}^{2} . \mathrm{s}^{-1}\right)$

$\mathrm{H}^{\prime} \quad$ Henry partition coefficient $\left(\mathrm{Pa} \cdot \mathrm{m}^{3} \cdot \mathrm{mol}^{-1}\right)$

$\mathrm{k}_{\mathrm{i}, \mathrm{A}} \quad$ Local mass transfer coefficient of component $\mathrm{i}$ in phase $\mathrm{A}\left(\mathrm{m} \cdot \mathrm{s}^{-1}\right)$

$\mathrm{K}_{\mathrm{S}} \quad$ Monod saturation constant $\left(\mathrm{g} \cdot \mathrm{m}^{-3}\right)$

M Molar mass $\left(\mathrm{g} \cdot \mathrm{mol}^{-1}\right)$

$\mathrm{p}, \mathrm{P} \quad$ Partial and total pressure $(\mathrm{Pa})$

$Q_{i} \quad$ Volumetric flow rate of phase $\mathrm{i}\left(\mathrm{m}^{3} \cdot \mathrm{s}^{-1}\right)$

$\mathrm{R} \quad$ Gas constant $\left(=8,314 \mathrm{~J} \cdot \mathrm{mol}^{-1} \cdot \mathrm{K}^{-1}\right)$

$r_{X} \quad$ Biomass growth rate $\left(\mathrm{g} \cdot \mathrm{m}^{-3} \cdot \mathrm{s}^{-1}\right)$

$\mathrm{S} \quad$ Substrate concentration $\left(\mathrm{g} \cdot \mathrm{m}^{-3}\right)$

$\mathrm{T} \quad$ Temperature $(\mathrm{K})$

$V_{i} \quad$ Volume of phase $i$ in the TPPB $\left(\mathrm{m}^{3}\right)$

$V_{R} \quad$ TPPB reactor volume

$V_{A}(b) \quad$ Molecular volume at the boiling point of the compound $A\left(\mathrm{~m}^{3} \cdot \mathrm{mol}^{-1}\right)$

X Biomass concentration $\left(\mathrm{g} \cdot \mathrm{m}^{-3}\right)$

$\mathrm{Y}_{\mathrm{X} / \mathrm{S}} \quad$ Biomass to substrate yield

$\mu_{\mathrm{i}} \quad$ Specific growth rate of the microorganisms in the i phase $\left(\mathrm{h}^{-1}\right)$

$\mu_{d} \quad$ Specific decay rate of the microorganisms $\left(\mathrm{h}^{-1}\right)$

$\mu_{\operatorname{Max}} \quad$ Maximum specific growth rate of the microorganisms $\left(\mathrm{h}^{-1}\right)$

v Kinematic viscosity $\left(\mathrm{m}^{2} \cdot \mathrm{s}^{-1}\right)$

$\rho_{\mathrm{i}} \quad$ Density of phase i $\left(\mathrm{kg} \cdot \mathrm{m}^{-3}\right)$

$\sigma \quad$ Surface tension $\left(N \cdot \mathrm{m}^{-1}\right)$

$\phi \quad$ Volume fraction of the phase i relative to the total working volume of the reactor 


\section{Abstract}

Biological treatments are used in gas treatment when containing volatile organic compounds (VOC). Key factor to enhance treatment efficiency is to maximize mass transfer from gas to liquid. VOCs can be removed from the gas flow by absorption in a separate gas-liquid contactor before entering a twophase partitioning bioreactor (TPPB) (Two-stage unit). The non-aqueous phase liquid (NAPL), a silicone oil in this study, is able to solubilize large amounts of hydrophobic VOCs while avoiding toxicity effects on the microorganisms.

The aim of this study is to provide a designing tool for the degradation process occurring in the TPPB. Simulations considering mass transfer coupled with biodegradation kinetics were considered when investigating the TPPB mechanisms. A single VOC (toluene) was first taken as a reference to assess the accuracy of the model in comparison with experimental results. A mixture of seven VOCs (toluene, m-xylene, 1,3,5 trimethylbenzene, n-heptane, ethyl acetate, methyisobutylketone and isopropyl alcohol) presenting a wide range of hydrophobicity was then implemented in the model considering no interaction regarding their biodegradation. Degradation kinetics of the mixture (representing an actual exhaust gas from an industrial plant) were compared with experimental results. The developed model tends to highlight that modeling results are closed to experimental results. The results delivered by the model shows that mass transfer, through the " $k_{\llcorner} a$ " value, is a key parameter to enhance efficiency of NAPL renewal by biological regeneration.

Corresponding author: annabelle.couvert@ensc-rennes.fr, +33 (0)2 23238048

\section{Keywords}

TPPB, Biodegradation, Absorption, Modeling, PDMS, VOCs

Graphical abstract 

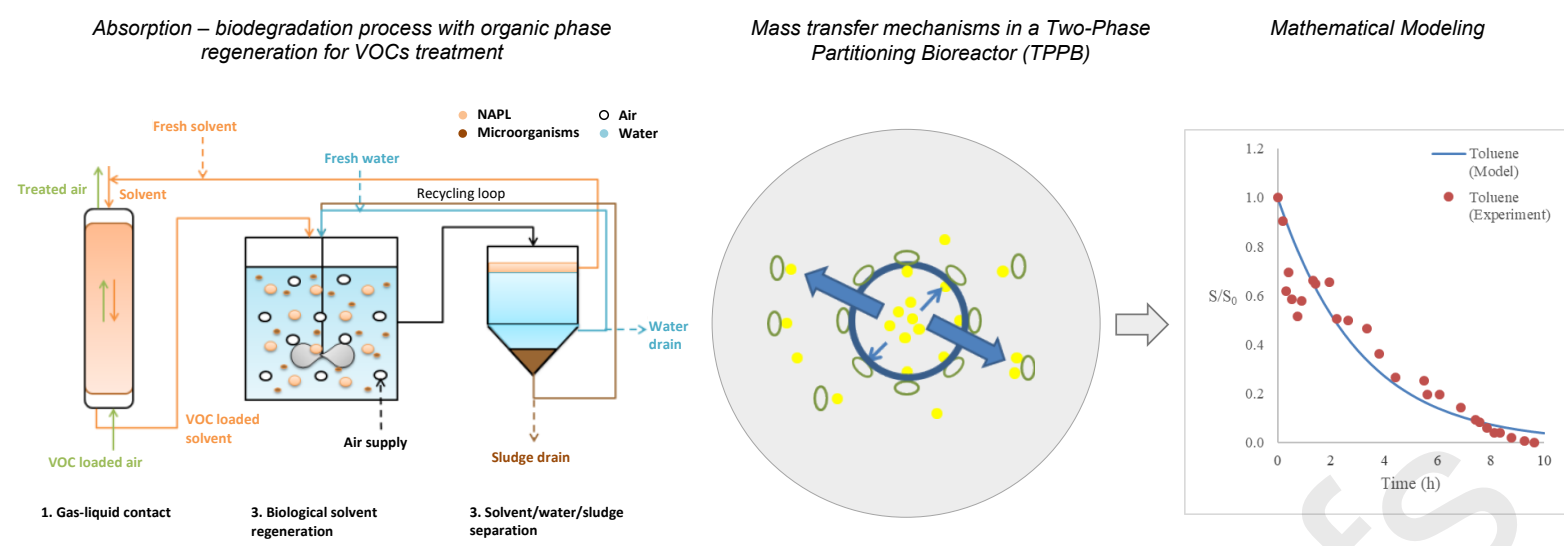

Highlights

- The modeling of the biodegradation of 7 VOCs in a pilot-scale TPPB is presented

- Model is validated by comparison to experimental data with toluene only and with the 7 VOCs

- Modeled results reveal 3 groups of molecules reacting differently to biodegradation

- Model shows that " $\mathrm{L}_{\mathrm{L}} \mathrm{a}$ " is a key parameter to enhance NAPL biological regeneration

- The developed model shows that modeling results are closed to experimental results

\section{Introduction}

Among the current environmental issues that our societies are facing today, air pollution is one of the most worrying. There is a growing concern about the direct and indirect effects of VOCs emissions on human health and the environment. Indeed, they induce cancers and congenital malformations and can modified the Chapman Cycle responsible for tropospheric ozone generation. It is therefore necessary to prevent atmospheric VOCs emissions from various industries [1].

Biological processes are gaining more and more interest in gas treatment as they allow to treat relatively high flow rates for an interesting cost [2]. One of major drawbacks of those processes regarding VOCs elimination is the low solubility of those compounds (mainly hydrophobic) in water, where microorganisms are growing and consuming VOCs. The toxicity of some of those compounds toward microorganisms can also be detrimental for the process performances. Two-Phase Partitioning Bioreactors (TPPBs) are a good alternative to classical bioreactors. The principle is based on the introduction of a Non-Aqueous Phase Liquid (NAPL), presenting higher affinity for the targeted VOCs 
than water, and an aqueous phase containing micro-organisms and nutriments required for their growth. Such a reactor can therefore be used to remove poorly soluble compounds in water and to increase their biodegradation rates [3-6].

TPPBs efficiency has already been proven in various applications [7-12]. Some studies focused on targeting parameters likely to reach high efficiencies, like temperature, phase volumetric ratio, microorganisms' concentration, or the selection of the organic phase $[13,14]$. The results help development of TPPB for gas treatment. But only little knowledge about degradation mechanisms is reported in the literature [15-17] and modeling could be useful for more accurate sizing of TPPB when implemented on gas treatment plant and for scale-up.

Many TPPB configurations can be set up, whether microorganisms are dispersed in the aqueous phase or attached to a solid phase, or considering the absorption and biodegradation steps occurring concomitantly or not [18-21]. Specific modeling has to be developed for each configuration considering particular mechanisms occurring within the TPPB [22]. In addition, modeling is usually conducted considering a single VOC [23-25]. But actual polluted gas streams generally contain a great number of VOCs, depending on the plant activity, that can be inconsistently absorbed in the NAPL and degraded by the microorganisms [2]. Studies considering biodegradation of a mixture of VOCs is very sparse in the literature [26]. There is a need to accurately anticipate those effects on TPPB performances and to develop modeling tool that can be used for either sizing purpose or for better operating the process onsite [22].

In this study, a mixture of 7 VOCs simulating an actual industrial effluent from a chemical reprocessing plant was chosen to assess the influence on the process performances. The 7 VOCs are toluene, $m$ xylene, 1,3,5 trimethylbenzene (TMB), $n$-heptane, ethyl acetate (ETOAc), methylisobutylketone (MIBK) and isopropyl alcohol (IPA). They present variable affinity for the NAPL and the aqueous phase, and different biodegradation rates that could significantly hinder the whole process efficiency. Besides, TPPB are usually sized by targeting a specific VOC. So it is crucial to assess the influence of a mixture of VOCs to properly dimension TPPB for the treatment of actual polluted gas streams, as they are usually composed of different VOCs.

This work presents a first approach for the modeling of the biodegradation of 7 VOCs in a pilot-scale Two-Phase Partitioning Bioreactor (TPPB). A model was developed based on the several mechanisms 
occurring within the TPPB responsible for VOCs elimination, i.e. mass transfer and biodegradation. The main purpose of the study is to initiate the first step by developing a mathematical tool that can be used to predict (design purpose) the dimensions of a TPPB or the efficiency of a running facility.

\section{Material and Methods}

\subsection{TPPB reactor setup}

Different TPPB's configuration can be proposed for gas treatment. The one chooses in this process is a 3-stage system as presented in Figure 1. The first stage uses a gas-liquid contactor to perform the VOC absorption in the NAPL. The second step consists of a TPPB allowing to regenerate the NAPL by performing VOC biodegradation. Regenerating the NAPL is essential to retrieve a high absorption capacity and to work in closed loop. The liquid phase (NAPL and water containing microorganisms) is finally sent in a separation step before recirculating in the gas-liquid contactor.

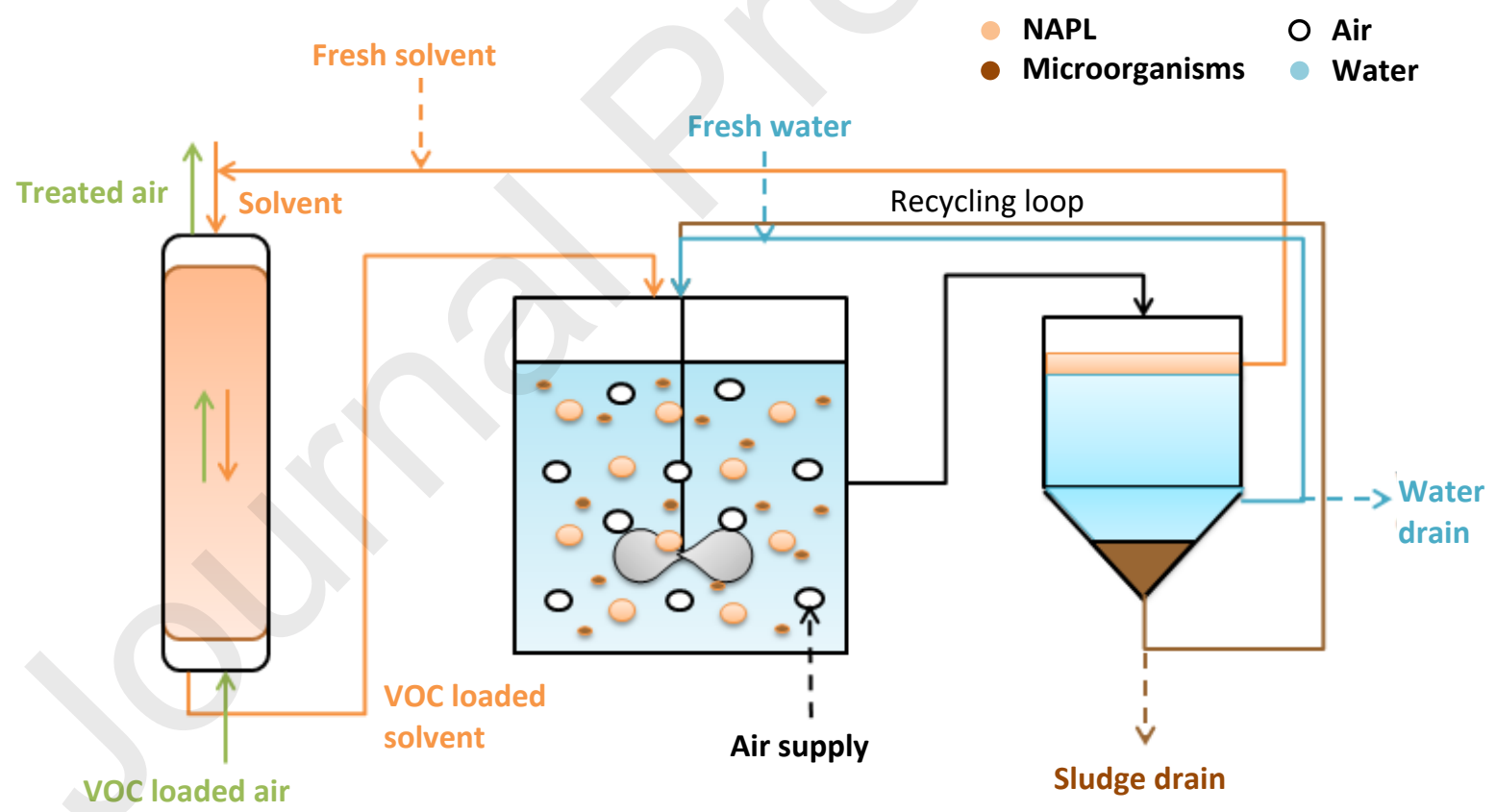

1. Gas-liquid contact

3. Biological solvent regeneration
3. Solvent/water/sludge separation

Figure 1: Absorption - biodegradation process with organic phase regeneration for VOCs treatment. 
This configuration, where absorption and biodegradation are conducted in separate modules, allows more control on each step and facilitates the establishment of the mechanisms.

The TPPB device used to conduct experiments is a standard stirred tank reactor run in batch mode with continuous gas stream for oxygenation (1-2 L. $\left.\mathrm{min}^{-1}\right)$. Diameter is $25 \mathrm{~cm}$ for a total volume of $12.3 \mathrm{~L}$. A water jacket is used for temperature regulation. A Rushton stirring device (6 pales) is set to insure correct mixing conditions.

The TPPB device is filled up to $10 \mathrm{~L}$ with a NAPL fraction of 0.25 (volumetric fraction) and 0.75 of aqueous phase. Aqueous phase contained activated sludge $\left(0.5 \mathrm{~g} \cdot \mathrm{L}^{-1}\right.$ of dry matter, from a wastewater treatment plant (Rennes, France)) and salts as nutrients for biomass needs. Stirring speed is set at 300 rpm, temperature at $25^{\circ} \mathrm{C}, \mathrm{pH}$ to 7 . Experiments are conducted after sludge acclimation $[27,28]$.

\subsection{Chemicals}

Silicone oil (polydimethylsiloxane, PDMS) is the NAPL used in this study. It is supplied by Bluestar Silicones company. Rhodorsil 47v20 is the specific oil chosen presented in Table 1.

Table 1: PDMS characteristics.

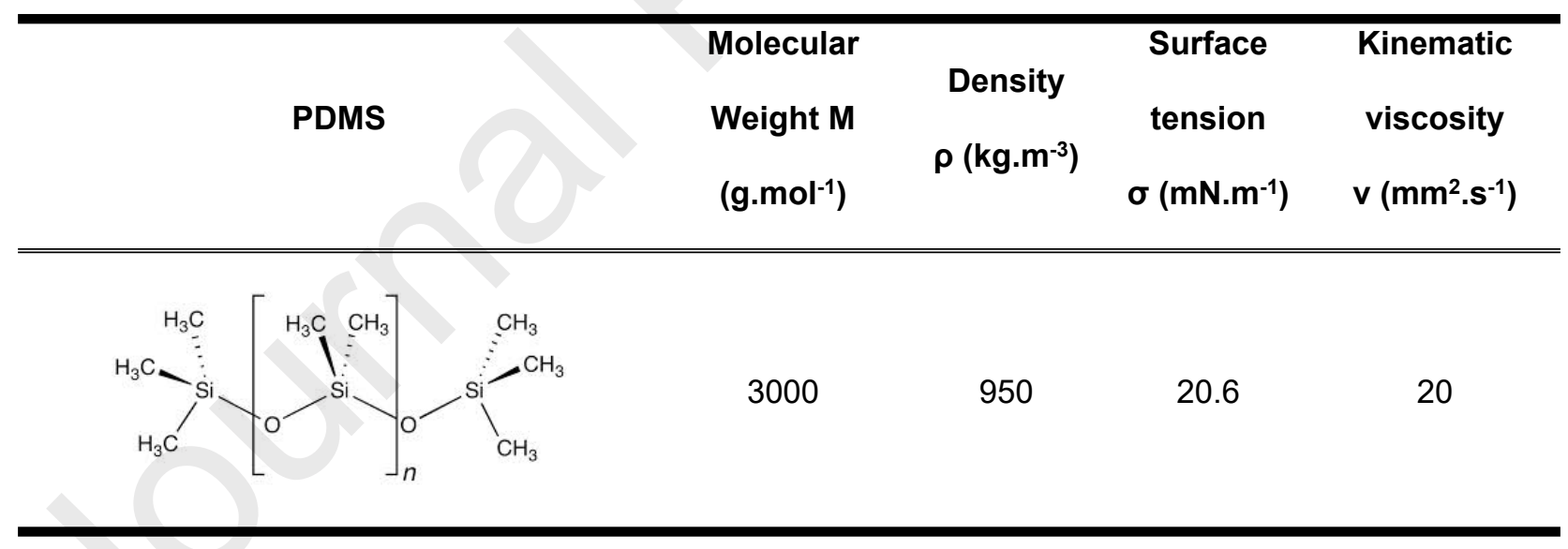

Toluene (99.8\%), 1,3,5-trimethylbenzene (97\%) and ethyl acetate (HPLC use, purity $\geq 99.7 \%$ ) are provided by Sigma-Aldrich. $m$-xylene $(99.5 \%)$ is provided by Janssen pharmaceutica NV. $n$-heptane (99.5\%) is from Prolabo. Isopropyl alcohol (HPLC use, 100\%) is provided by VWR Chemicals. Finally, methyl isobutyl ketone (99.5\%) is provided by Acros Organics.

\subsection{Diffusion coefficient}

The diffusion coefficients are measured by using a thermogravimetric analyzer (TGA) (Hidden isochema Ltd, IGA 003, Japan). The IGA 003 design integrates precise computer-control and measurement of 
precise mass, pressure and low temperature variations which allow an automated and reproducible acquisition of absorption phenomenon. Microbalance is enclosed by a thermostatic enclosure made of steel under controlled pressure. The measurements were carried out using approximately $120 \mathrm{mg}$ of silicone oil. Sample is degassed by applying a high vacuum $\left(10^{-7} \mathrm{mbar}\right)$ using a first diaphragm pump and a turbomolecular pump. Temperature is controlled with a thermostat (using water as a heat-transfer fluid). The first pressure is applied when the set temperature is reached and the sample mass is stabilized. The mass measured increases due to VOC absorption in the NAPL, up to reach a plateau corresponding to the equilibrium. Measures are conducted using successive pressure of $2-3.5-5-$ $6.5-8-9.5 \mathrm{mbar}$ at a temperature of $298.15 \mathrm{~K}$. Buoyancy corrections are necessary due to Archimedes' law working on the elements that take part in the measure [29].

\subsection{Biodegradation experiment}

Experiments were conducted using either pure toluene or mixture of the 7 VOCs which simulate an industrial effluent (Table 2). The 7 VOCs were identified by screening the atmosphere of a chemical reprocessing plant. Several samplings were made on the off-gas and VOC concentrations were measured by Gas Chromatography with Flame Ionization Detector (GC-FID). Characteristics of the GCFID are presented Table 3.

Table 2: Composition of the synthetic industrial effluent.

\begin{tabular}{|c|c|c|c|c|c|c|}
\hline VOC & Tolu $m$-xylene & TMB & $n$-heptane & ETOAC & MIBK & IPA \\
\hline Composition (\%) & 8 & 4 & 18 & 22 & 25 & 16 \\
\hline 2 & Column type & $\begin{array}{c}\text { Injection } \\
\text { temperature }\end{array}$ & $\begin{array}{l}\text { Dete } \\
\text { tempe }\end{array}$ & & $\begin{array}{c}\text { Oven } \\
\text { temperature }\end{array}$ & Gas vector \\
\hline Characteristics & $\begin{array}{c}\text { CP-FFAD } \\
25 \times 0.32 \mathrm{~mm}\end{array}$ & $125^{\circ} \mathrm{C}$ & 190 & & $40^{\circ} \mathrm{C}$ & $\mathrm{N}_{2}$ at $2.5 \mathrm{kPa}$ \\
\hline
\end{tabular}


For the biodegradation experiments, $500 \mu \mathrm{L}$ were sampled using a syringe through a septum and injected in the GC-FID to be analyzed. Experiments were conducted for $10 \mathrm{~h}$ for toluene biodegradation alone and for $50 \mathrm{~h}$ for VOCs mixture biodegradation.

\section{Model development}

\subsection{Reactor}

The NAPL selected for this study is silicone oil as it presents the main qualities required, such as biocompatibility, non-biodegradability, water immiscibility, and satisfactory affinity for hydrophobic VOC [30]. Some model developments have been presented in literature [23-25,31,32]. All of them are based on the expression of mass transfer between the different phases and biodegradation kinetics. As many configurations could be set up for TPPBs (e.g. direct injection of gaseous stream in the TPPB rather than a separate column), many model expressions can be proposed. The one proposed here is applied to the specific configuration of our TPPB.

\subsection{TPPB Model}

\section{Model Equations}

The mathematical model is based on several key parameters such as the NAPL chemical nature, the aqueous phase composition and their flow rates, the partition of each VOC between two phases (gas and liquid or liquid and liquid), mass transfer kinetics of VOC between the different phases, and biodegradation kinetics.

In a batch reactor with biodegradation conducted in an aqueous phase, a system of equations determines the biodegradation kinetics [33]: substrate concentration (S) variation is related (Eq. 3-3) to the microorganisms growth $\left(r_{X}\right)$ (Eq. 3-2) and the biomass to substrate conversion yield $\left(Y_{X / S}\right)$ (Eq. 3-1).

$$
\begin{gathered}
Y_{\bar{S}}=-\frac{\delta X}{\delta S} \\
r_{X}=\frac{d X}{d t}=\mu \cdot X
\end{gathered}
$$




$$
\frac{d S}{d t}=-\frac{r_{X}}{Y_{\bar{X}}}
$$

Kinetics can be described by Monod equation (Eq. 3-4), using the maximum specific growth rate $\mu_{\operatorname{Max}}$ and the Monod saturation constant $\mathrm{K}_{\mathrm{S}}$, when no inhibition phenomenon appears [34] (substrate concentrations remain low enough and by-products evacuate rapidly).

$$
\mu=\frac{\mu_{\operatorname{Max}} \cdot S}{K_{S}+S}
$$

When microorganisms are in presence of a mixture of substrate, specific growth rate due to each substrate can be added to obtain a global specific growth rate (Eq. 3-5) [35].

$$
\mu=\sum_{i}\left(\frac{\mu_{\text {Max }_{i}} \cdot S_{i}}{K_{S_{i}}+S_{i}}\right)
$$

This equation (Eq. 3-5) was used on the assumption that there is no interaction between each substrate.

VOCs are present first in the NAPL, after absorption through the packed column, and have to be transferred in the aqueous phase to be consumed. Equations have to be modified in consequence [16]. In a continuous reactor containing NAPL, other terms are added to the biodegradation equations to take into account transfer of VOCs between NAPL and aqueous phase, balance between the output and the input and a potential purge [36].

Assumption is made that there is no microbial growth within NAPL. A Monod equation can then be used to describe microbial growth in the aqueous phase $\left(\mu_{\mathrm{w}}\right)($ Eq. 3-6) [23].

$$
\mu_{w}=\mu_{M a x}\left(\frac{S_{w}}{K_{S}+S_{w}}\right)-\mu_{d}
$$

Where $\mu_{\operatorname{Max}}$ is the maximum specific growth rate, $\mathrm{K}_{\mathrm{S}}$ the Monod saturation constant, $\mathrm{S}_{\mathrm{w}}$ the substrate concentration in the aqueous phase, and $\mu_{d}$ the specific decay rate of the microorganisms.

It is assessing that substrate inhibition can be omitted as TPPB is used to treat poorly hydrophilic compounds and presenting therefore low solubility for aqueous phase.

Balance for biomass in aqueous phase can be written as follows (Eq. 3-7)[23]. 


$$
\frac{d X_{w}}{d t}=\mu_{w} \cdot X_{w}-\frac{Q_{w}}{V_{w}} \cdot X_{w}
$$

Aqueous phase as well as NAPL can be renewed continuously to avoid biomass and metabolite accumulation or to provide nutrients, mostly through the aqueous phase. NAPL is not necessarily renewed. Mass balance for VOCs in the different phases can then be written as follows (Eq. 3-8).

$$
\frac{d S_{w}}{d t}=\left(k_{L}^{\frac{N A P L}{w}} a\right)_{V O C}\left(\frac{S_{N A P L}}{\frac{H K_{A P} C_{L}}{w}}-S_{w}\right)-\frac{\mu_{w}}{Y_{\bar{X}}} \cdot X_{w}-\frac{Q_{w}}{V_{w}} \cdot S_{w}
$$

First term in this equation describes mass transfer between the NAPL and the aqueous phase, as presented by the Lewis and Whitman model. " $\mathrm{k}_{\mathrm{L}} \mathrm{a}$ " refers to the local mass transfer coefficient and $\mathrm{H}$ is the partition coefficient between two phases, defined (Eq. 3-9).

$$
C_{G}=H \cdot C_{L}
$$

Second term in this equation refers to the VOC biodegradation by microorganisms. Last term is related to the purge of the aqueous phase.

Mass balance for VOC can be described in the NAPL as follows (Eq. 3-10) $[23,37]$.

$$
\frac{d S_{N A P L}}{d t}=-\left(k_{L}^{\frac{N A P L}{w}} a\right)_{V O C}\left(\frac{C_{N A P L}}{\frac{H K Q \varphi_{L}}{w}}-S_{w}\right)\left(\frac{\phi_{N A P L}}{\phi_{w}}\right)-\frac{Q_{N A P L} \cdot\left(S_{N A P L, i n}-S_{N A P L}\right)}{\phi_{N A P L} \cdot V_{R}}
$$

The model presented above involves a certain number of parameters and variables. One of the objectives of this modeling work is to predict the dimensions of a treatment facility for biodegradation step. It is therefore necessary to know all parameters available in the literature.

\section{Data compilation}

Literature review was carried out to assess availability of the data required by the mathematical model proposed (parameters of biodegradation, equilibrium and mass transfer mainly). The aim of this study is to propose a mathematical model and determine how it can be run (knowing the parameters available in literature or the one that have to be measured).

Parameters occurring in equations can be gathered in three groups: transfer and equilibrium (partition coefficient and mass transfer coefficient), biodegradation kinetics $\left(\mu_{\mathrm{Max}}, \mathrm{K}_{\mathrm{S}}, \mathrm{Y}_{\mathrm{X} / \mathrm{S}}\right)$, and the running parameters (such as the volume ratio between Non-Aqueous Phase Liquid (NAPL) and liquid phases flow rates). 
Biodegradation kinetic parameters can be found in the literature for most of the VOCs [34].

Equilibrium parameters are not much available in literature. Values are specific to the NAPL used in the process, so it is difficult to find the exact couple (VOC associated to the NAPL). As it is an essential data for this project, partition coefficients have been measured for all the 7 VOCs considered in silicone oil, the NAPL selected in this study [38].

Diffusion coefficients are also essential to describe both biodegradation mechanisms and absorption (first step of the process). A certain number of models and correlations are presented for absorption, based on mass transfer occurring in the column. Those models require the appreciation of the diffusion coefficient, that have therefore to be known (by experimental determination or calculated). For the purpose of a global modeling work, diffusion coefficient calculation was investigated and compared with experimental results. Indeed, semi-empirical equations can be used to calculate diffusion coefficients [39]. Two models are presented in literature and compared to experimental values obtained by thermogravimetric analysis. It is usually preferable to consider experimental values since model can be inaccurate, especially depending on the organic phase used [40]. Scheibel model (Eq. 3-11) as well as Hayduk \& Minas models (Eq. 3-13) were compared to the experimental values to assess their accuracy.

$$
\begin{gathered}
D_{V O C-N A P L}=\frac{K \cdot T}{\left(V_{V O C}^{(b)}\right)^{1 / 3} \cdot \eta_{N A P L}} \\
K=8.2 \cdot 10^{-8}\left[1+\left(\frac{3 \cdot V_{N A P L}^{(b)}}{V_{V O C}^{(b)}}\right)^{2 / 3}\right] \\
D_{V O C-N A P L}=\frac{13.26 \cdot 10^{-5}}{\left(V_{V O C}^{(b)}\right)^{0.589} \cdot \eta_{N A P L}^{1.14}}
\end{gathered}
$$

\subsection{Model solution}

The differential equations were numerically solved using the Ordinary Differential Equation solver of the software Scilab in a home-made modeling environment. Runge-Kutta fourth-order method is used to approximate solutions of differential equations. 


\section{Results and Discussion}

\section{Diffusion coefficients}

TGA results are treated using diffusion model presented by Shiflett and Yokozeki [41]. The solubility of VOCs in PDMS can be determinate knowing the pressure applied and the final concentration in the liquid (with mass measure acquisition) using Yokoseki model [42]. This model assumes that convection phenomenon can be neglected, unidimensional diffusion is considered along axis $z$, temperature and pressure are constants during the measure.

Experiments are conducted at pressure allowing diffusion in an infinite diluted solution. Fick Law can be written (Eq. 4-1).

$$
\frac{\partial C}{\partial t}=D \frac{\partial^{2} C}{\partial^{2} t}
$$

Conditions are $\mathrm{C}=\mathrm{C}_{0}$ at $\mathrm{t}=\mathrm{t}_{0}$ for $0<\mathrm{z}<\mathrm{L}$, and $\mathrm{C}=\mathrm{C}_{\mathrm{S}}$ when $\mathrm{t}>\mathrm{t}_{0}$ and $\mathrm{z}=0$.

$$
\left(\frac{\partial C}{\partial t}\right)_{L}=0
$$

$\mathrm{C}\left(\mathrm{mol} \cdot \mathrm{m}^{-3}\right)$ is VOC concentration in NAPL, $t(\mathrm{~s})$ is time, $\mathrm{z}(\mathrm{m})$ height, $\mathrm{L}(\mathrm{m})$ is NAPL height in the basket, with $z=0$ corresponding to the liquid-gas interface. $C_{0}$ is the initial VOC concentration, and D diffusion coefficient $\left(\mathrm{m}^{2} \cdot \mathrm{s}^{-1}\right)$. C can be calculated using Laplace transform (Eq. 4-3).

$$
C=C_{0}\left[1-2\left(1-\frac{C_{0}}{C_{S}}\right)\right] \sum_{n=0}^{\infty} \frac{\exp \left(-\lambda_{n}^{2} D t\right) \sin \left(\lambda_{n} z\right)}{L \lambda_{n}}
$$

With $\lambda_{n}=\frac{\left(n+\frac{1}{2}\right) \pi}{L}$

$\mathrm{n}$-value is chosen to 15 to obtain sufficient precision for $\mathrm{C}$. Non-linear regression is used to determine coefficient $D$ for every pressure, imposing that least-square errors are minimized between experimental values and calculated values using Excel Solver (conditions are fixed as follows: maximum time $100 \mathrm{~s}$, iterations 1000 , precision of $10^{-7}$, tolerance $1 \%$, convergence $10^{-5}$, GRG nonlinear and central derivation). Results are presented in Table 4. 
Table 4: Diffusion coefficient for the 7 VOC in PDMS 20 compared to Scheibel model and Hayduk and Minas model (Relative error), $\mathrm{T}=25^{\circ} \mathrm{C}$.

\begin{tabular}{|c|c|c|c|}
\hline VOCs & $\begin{array}{l}\text { D experimental } \\
\qquad\left(10^{-10} \mathrm{~m}^{2} \cdot \mathrm{s}^{-1}\right)\end{array}$ & $\begin{array}{c}\text { D Scheibel } \\
\text { (Relative error \%) } \\
\left(10^{-10} \mathrm{~m}^{2} . \mathrm{s}^{-1}\right)\end{array}$ & $\begin{array}{l}\text { D Hayduk-Minas (Relative error \%) } \\
\qquad\left(10^{-10} \mathrm{~m}^{2} \cdot \mathrm{s}^{-1}\right)\end{array}$ \\
\hline Toluene & $3.96 \pm 0.47$ & $0.53(-86)$ & $2.36(-38)$ \\
\hline$m$-xylene & $5.74 \pm 0.71$ & $0.50(-91)$ & $2.00(-65)$ \\
\hline TMB & $4.85 \pm 1.21$ & $0.45(-92)$ & $1.51(-73)$ \\
\hline$n$-heptane & $4.95 \pm 0.35$ & $0.48(-90)$ & $1.75(-64)$ \\
\hline ETOAC & $6.39 \pm 0.70$ & $0.54(-92)$ & $2.51(-61)$ \\
\hline MIBK & $5.64 \pm 1.09$ & $0.50(-91)$ & $2.00(-65)$ \\
\hline IPA & $7.25 \pm 0.95$ & $0.60(-92)$ & $3.45(-52)$ \\
\hline
\end{tabular}

In view of the values obtained, there is no significant influence of pressure on the diffusion coefficient value, justifying the assessment of diffusion in an infinitely diluted solution.

Significant differences were noticed between experimental values and calculated values. Models used to calculate diffusion coefficients derived from the Stokes-Einstein model, only considering the size of the molecule diffusing in the liquid and not eventual interactions between those molecules and the liquid. This could explain the differences between the values. However, values obtained by Hayduk \& Minas (model developed for organic phases) were closer than those obtained using Scheibel model. For purpose of a size calculation in a modeling work, it is therefore preferable to determine experimental diffusion coefficient values rather than calculated values using the models.

Table 5: Diffusion coefficient of the 7 VOC in PDMS 20 and in water.

\begin{tabular}{cccccccc}
\hline $\begin{array}{c}\text { D } \\
\left(\times \mathbf{1 0} \mathbf{- 1}^{-1} \mathbf{m}^{\mathbf{2}} \mathbf{s}^{-1}\right)\end{array}$ & Toluene & $\boldsymbol{m}$-xylene & TMB & $\boldsymbol{n}$-heptane & ETOAc & MIBK & IPA \\
\hline \hline PDMS & 3.96 & 5.74 & 4.85 & 4.95 & 6.39 & 5.64 & 7.25 \\
\hline Water & 8.60 & 7.80 & 7.23 & 7.00 & 9.70 & 7.80 & 13.0 \\
\hline
\end{tabular}


Diffusion coefficients clearly decrease for every compound in silicone oil compared to diffusion coefficients in water as presented in Table 5. This result can be correlated to the increase of the kinematic viscosity $\left(20 \mathrm{~mm}^{2} . \mathrm{s}^{-1}\right.$ for PDMS against $1 \mathrm{~mm}^{2} . \mathrm{s}^{-1}$ for water). Diminution in mass transfer is unfavorable for the absorption capacity of silicone oil, but could be counterbalanced by the high affinity of hydrophobic VOCs for this phase [13].

\section{Biodegradation model}

The model developed can be considered to compare both continuous or batch experiments. All the parameters used in the equations have been gathered Table 6 .

Table 6 : Biodegradation and mass transfer parameters of the 7 VOCs according to the literature.

\begin{tabular}{|c|c|c|c|c|c|c|c|}
\hline & Toluene & $m$-xylene & TMB & $n$-heptane & ETOAC & MIBK & IPA \\
\hline $\begin{array}{c}\mathrm{H}^{\mathrm{VOC}}{ }_{\mathrm{NAP} / \mathrm{w}} \\
\left(\mathrm{m}^{3} \cdot \mathrm{m}^{-3}\right)\end{array}$ & 318.1 & 1064.3 & 3063.2 & 88620.8 & 2.2 & 8.1 & 0.04600 \\
\hline $\begin{array}{l}Y_{X / v O C} \\
\left(g \cdot g^{-1}\right)\end{array}$ & 0.65 & 0.35 & 0.3 & 0.45 & 0.365 & 0.3 & 0.3029 \\
\hline $\begin{array}{c}\mathrm{K}_{\mathrm{S}} \\
\left(\mathrm{g} \cdot \mathrm{m}^{-3}\right)\end{array}$ & 2.5 & 0.11 & 8.99 & 5.22 & 183 & 10.01 & 378.01 \\
\hline $\begin{array}{c}\mu_{\operatorname{Max}} \\
\left(m^{3} \cdot g^{-1} \cdot h^{-1}\right)\end{array}$ & 0.42 & 0.03 & 0.0946 & 0.086 & 2.45 & 0.14 & 0.0393 \\
\hline $\begin{array}{c}\left(k^{N A P / w_{L}} \mathbf{a}\right)_{\text {Voc }} \\
\left(h^{-1}\right)\end{array}$ & 40 & 37.9 & 36.0 & 35.2 & 41.1 & 85.9 & 45.6 \\
\hline
\end{tabular}

" $\mathrm{L}_{\llcorner} a$ " value was measured for toluene in the same conditions than this study [28]. This value is used as a reference to calculate " $\mathrm{k}_{\mathrm{L}} \mathrm{a}$ " values of other VOCs using (Eq. 4-4) [23].

$$
\frac{k_{L} a_{V O C}}{k_{L} a_{r e f}}=\frac{\left(1 / V_{m, V O C}^{b}\right)^{0.4}}{\left(1 / V_{m, r e f}^{b}\right)^{0.4}}
$$


Model is established to predict TPPB degradation efficiency regarding VOC alone or in a mixture. However, experimental results for batch reactor are only available for toluene to conduct a quantitative comparison. They are presented in Figure 2, also displayed the corresponding modeled values.

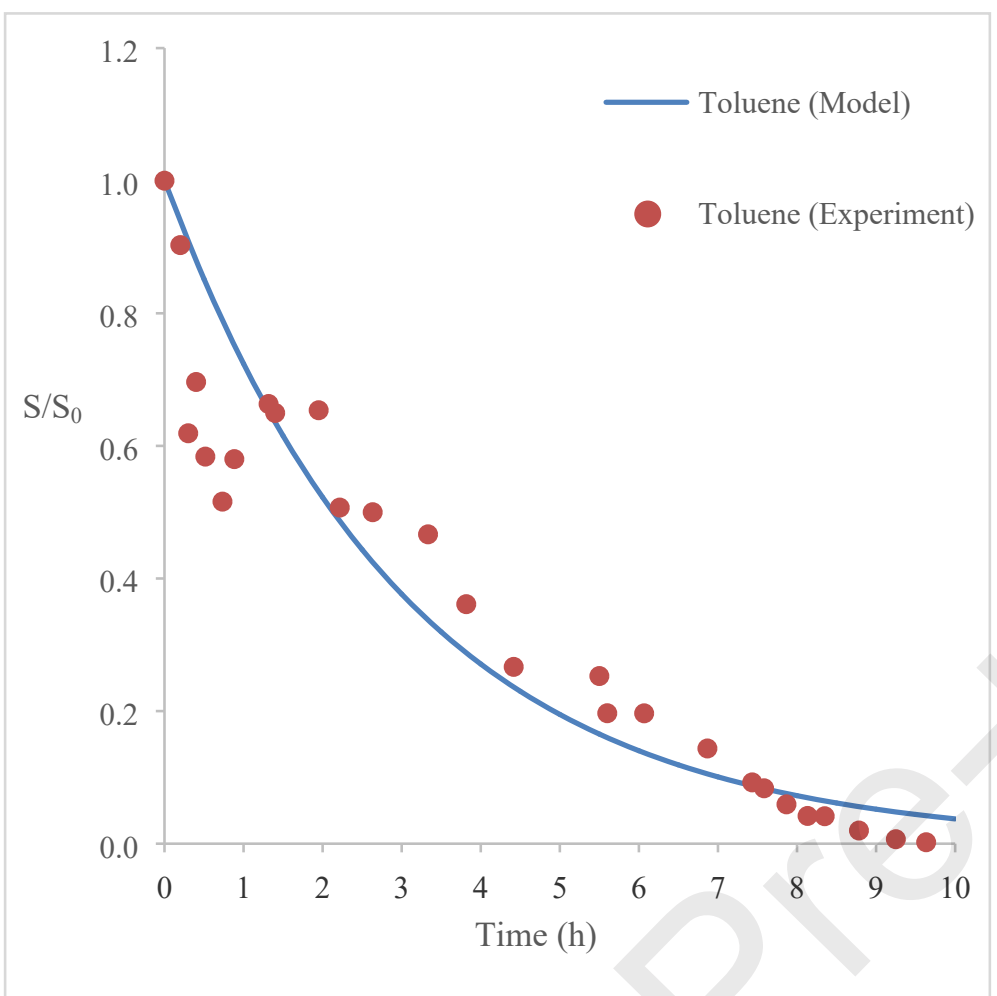

Figure 2: Toluene biodegradation in a TPPB, experimental and modeled values.

Initial concentration in toluene was $500 \mathrm{~g} \cdot \mathrm{m}^{-3}$ for a total duration of $10 \mathrm{~h}$. Experiments were conducted on the TPPB at laboratory scale ( $10 \mathrm{~L}$ ) using $25 \%$ of organic phase and a stirring speed of $300 \mathrm{rpm}$. Modeled results are close to the experimental values. Larger disparity can be seen at the beginning of the experiment (during the first two hours), with a relative error up to $35 \%$. Those differences can be explained by the time necessary to reach equilibrium for toluene between the three phases: gaseous, non-aqueous and aqueous. Nevertheless, modeled values present the same trend than experimental values and can assess that our assumption on mass transfer and biodegradation are justified. Similarity between results during almost the entire experiment suggests that the model can be used not only for steady state removal rates but also for dynamic conditions.

The model was used to appreciate the influence of the " $k_{L} a$ " value, essential to set up an accurate model. " $\mathrm{L}_{\mathrm{L}} \mathrm{a}$ " is a key factor governing mass transfer between the different phases, so it is essential to assess its influence on the model. Figure 3 presents normalized toluene concentration $\mathrm{S} / \mathrm{S}_{0}$ calculated with 
different " $k_{\llcorner} a$ " values (from 20 to $100 h^{-1}$, interval of $10 h^{-1}$ ). "k $k_{L} a$ " value was measured for toluene as 40 $\mathrm{h}^{-1}$ in the conditions of this study.

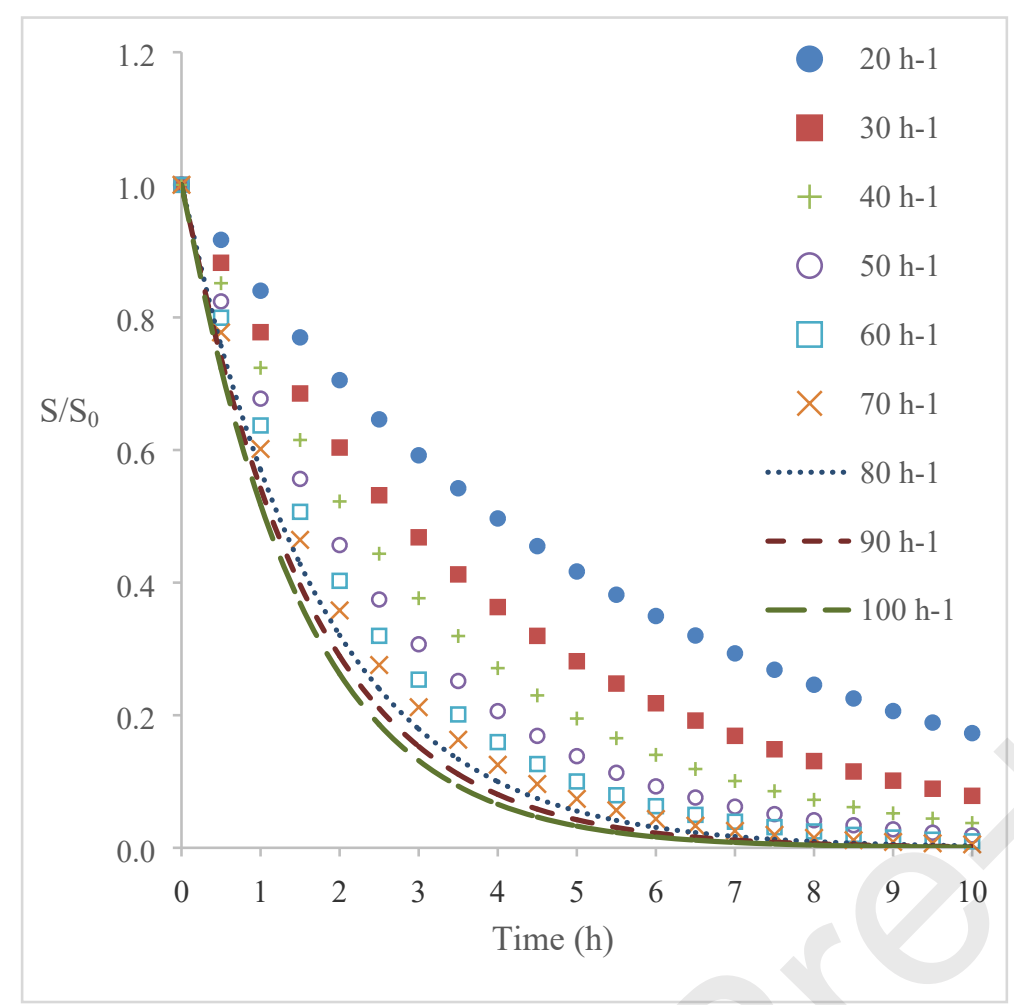

Figure 3: Influence of « $k_{\mathrm{L}} \mathrm{a}$ » value on toluene biodegradation.

Most differences appear especially for low " $\mathrm{k}_{\mathrm{L}} \mathrm{a}$ " values. For example, half-time reaction (amount of time needed for VOCs concentration to decrease by half compared to its initial concentration) is falling down from 4.25 to $2.45 \mathrm{~h}$ for " $\mathrm{k}_{\mathrm{L}} \mathrm{a}$ " values of 20 and $40 \mathrm{~h}^{-1}$ respectively, while it is only reducing from 1.6 to 1.4 $h$ when " $k_{\llcorner} a$ " is 80 and $100 h^{-1}$. This result leads us to believe that mass transfer, through " $k_{\llcorner} a$ ", is a key parameter to enhance efficiency of NAPL renewal by biological regeneration.

Because of the absence of measurements, the experimental results in case of a multicomponent mixture can only be compared qualitatively. However, these results can also illustrate whether the trend proposed by the model follows the same behaviour as the experiment (Figure 4). 

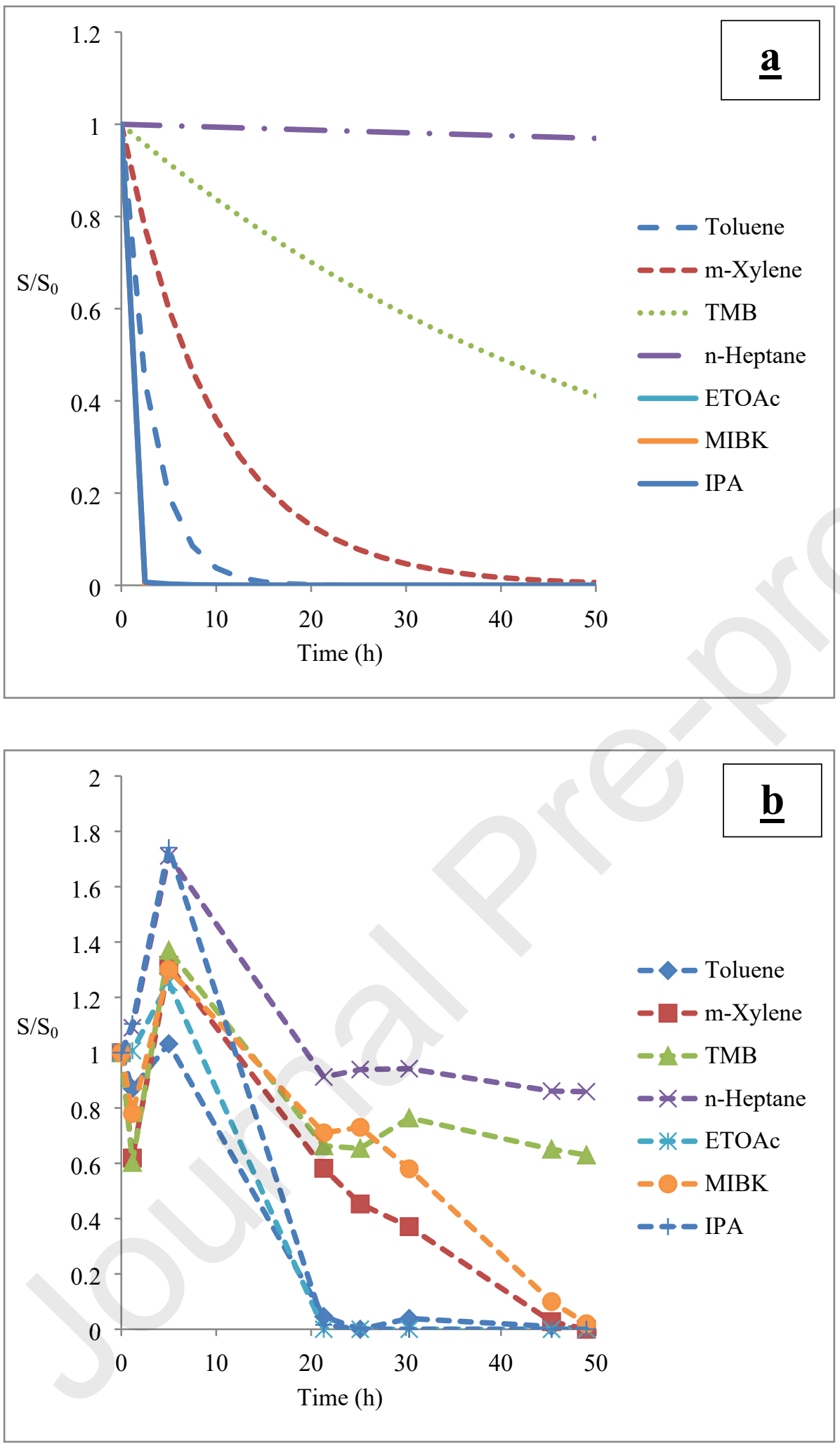

Figure 4: $n$-heptane, ETOAC, IPA, MIBK, toluene, m-xylene, and TMB normalized concentrations evolution in multicomponent mixture according to $(\underline{a})$ model results and $(\underline{b})$ experimental results. 
Three groups can be distinguished reacting differently toward biodegradation, according to the modeled results: more easily biodegradable components (IPA, MIBK and ETOAc) to the more reluctant ( $n$ heptane and TMB) and intermediate (toluene and $m$-xylene). Those results suggest that VOCs' affinity for the organic phase is one of the more determining factors for VOCs consumption kinetics. Indeed, affinity for the NAPL increases as follows: $n$-heptane, TMB, $m$-xylene, toluene, MIBK, ETOAc, IPA, according to the partition coefficient (Table 6). The more the affinity of the VOC is important for the aqueous phase, the more it is transferred from the organic phase to the aqueous phase, and might be consumed by microorganisms.

Compared to the experimental results, the same trend appears for the different VOCs. $n$-heptane so as TMB are hardly degraded by microorganisms, probably because of their low affinity for water. Lack of data between $5 \mathrm{~h}$ and $20 \mathrm{~h}$ cannot justify when IPA and ETOAc have totally been consumed. However, same path appears revealing three groups of degradation. Even though the biodegradation kinetics data were taken from the literature, namely related to experimental conditions that are not exactly similar to the study, for example with different microorganisms, experimental studies highlight that the microorganisms' nature is not of major concern for the TPPB performances [19]. The microorganisms are acclimated to the mixture of VOCs that maximize the biodegradation kinetics by adaptation of the microorganisms [30].The biodegradation kinetics, either if it is obtained with pure strain or with mixed consortium highlight the refractory nature of the VOC and thus its ability to be degraded by the microorganisms $[19,22,23]$. As those results are obtained only with data from the literature and present good agreement with the experimental results (Figure 4), the model could be used with other VOCs mixtures on condition that biodegradation kinetics are available (from the literature or from experimental measurement), especially since the VOC considered in this work present great variability of characteristics (in terms of hydrophobicities and chemicophysical properties).

This model assumes that there is no interaction between VOCs degradation in mixture. It can be supposed that this could be the case for VOCs with low affinity for aqueous phase, where they are present in very low quantities. But VOCs presenting high affinity for aqueous phase could present some interaction as they can be transferred in the aqueous phase more rapidly and in more important concentration. The usual Monod Equations could be substituted by biodegradation kinetics considering those interactions. As it is specific to the VOCs pairing, it might be difficult to find in the literature and should be determined experimentally. Another explanation can be found in the presence of the 
metabolites (degradation by-products). When a VOC is consumed by micro-organisms, it is metabolized in other compounds that can have influence on other compounds degradation. For example, one metabolite of MIBK degradation is ETOAc [47] that simply increase ETOAc concentration in TPPB that have to be consumed by the microorganisms. A different order of priority can also appears in mixture, with the consumption of one substrate preferred to another by the microorganisms [48]. Selection of the more adapted NAPL can therefore be conducted, by assessing the absorption performances toward the VOCs mixture [49] and also by evaluating the regeneration of the NAPL by the microorganisms [50] to recover the optimal treatment efficiencies [51].

As the model shows similar trends compared to experimental results, it could be used either for sizing purpose or to anticipate performances of a running process. The TPPB model can be coupled with the absorption efficiency of the column (obtained with equilibrium modeling or rate-based approach), that allows calculation of the VOCs concentrations in the NAPL entering the TPPB [52]. The model developed in this work allows to determine the regeneration ratio of the NAPL. If it is for design purpose, it can provide the volume of the TPPB required so that the NAPL recycled to the column presents sufficient absorption capacity to recover the targeted concentration in VOCs given by the emission standards. If it is used for process operation, it allows to calculate VOCs' emissions depending on the regeneration performances and the operating parameters of the process.

\section{Conclusions and perspectives}

The modeling of the biodegradation of a single VOC (toluene) and a mixture of $7 \mathrm{VOCs}$, representing an actual polluted gas stream from a chemical reprocessing plant, was conducted on a Two-Phase Partitioning Bioreactor (TPPB). The model is based on mass transfer between the NAPL and the aqueous phase containing the microorganisms and biodegradation of the VOCs in the aqueous phase. It considers concomitant absorption and biodegradation of the mixture of VOCs in the TPPB. The model is validated by comparison with experimental results generated on a pilot-scale TPPB. The developed model tends to show that modeling results are close to experimental results. It is particularly the case for toluene where results from modeling are in good accuracy with experiments. The modeled results for the biodegradation of the mixture of VOCs also present close trends with the experimental results. The model illustrates that particular attention should be addressed to the " $k_{\llcorner} a$ " value, as the sensibility 
of the regeneration of the NAPL is closely linked to the mass transfer from the NAPL to the aqueous phase.

The developed model successfully evaluates regeneration of the NAPL with only data taken from the literature, that is of great importance to accurately dimension a gas treatment process for an industrial plant. It is suggested that conditions of experiment must be well defined to be compared with the model. One can especially take attention on the model validity for each VOC taken separately, mostly regarding their hydrophilic character. It can generate different biodegradation kinetics and unequal VOCs consumption. Also, for a mixture of VOCs it can be assessed if potential competition phenomenon should be considered to strengthen the model.

Results obtained in this work are likely to be used for a first TPPB design for VOC treatment. In combination with absorption modeling in a gas-liquid contactor, a global tool could be proposed to dimension an entire process coupling absorption and biodegradation for VOCs elimination in a polluted gas stream containing a great diversity of VOCs.

\section{Acknowledgments}

The authors want to thank the French governmental agency ADEME for the CORTEA funding ( $\mathrm{n}^{\circ}$ 1881C0001). The authors are also very grateful to Sylvain Giraudet for his support during TGA experiments and Luiza Rojas for the biodegradation experiments.

\section{References}

[1] M. Roustan, Transferts gaz-liquide dans les procédés de traitement des eaux et des effluents gazeux, Tec\&Doc, Lavoisier, Paris, 2003.

[2] P. Le Cloirec, Les composés organiques volatiles dans l'environnement, Tec\&Doc, Lavoisier, Paris, 1998.

[3] F. Heymes, P. Manno-Demoustier, F. Charbit, J.L. Fanlo, P. Moulin, A new efficient absorption liquid to treat exhaust air loaded with toluene, Chemical Engineering Journal. 115 (2006) 225231. https://doi.org/10.1016/j.cej.2005.10.011.

[4] B. Ozturk, D. Yilmaz, Absorptive Removal of Volatile Organic Compounds from Flue Gas Streams, Process Safety and Environmental Protection. 84 (2006) 391-398. https://doi.org/10.1205/psep05003.

[5] K. Bay, H. Wanko, J. Ulrich, Absorption of Volatile Organic Compounds in Biodiesel: Determination of Infinite Dilution Activity Coefficients by Headspace Gas Chromatography, Chemical Engineering Research and Design. 84 (2006) 22-28. https://doi.org/10.1205/cherd.05050.

[6] F. Lalanne, L. Malhautier, J.-C. Roux, J.-L. Fanlo, Absorption of a mixture of volatile organic compounds (VOCs) in aqueous solutions of soluble cutting oil, Bioresource Technology. 99 (2008) 1699-1707. https://doi.org/10.1016/j.biortech.2007.04.006.

[7] P. San-Valero, C. Gabaldón, J.M. Penya-roja, G. Quijano, Enhanced styrene removal in a twophase partitioning bioreactor operated as a biotrickling filter: Towards full-scale applications, Chemical Engineering Journal. 309 (2017) 588-595. https://doi.org/10.1016/j.cej.2016.10.054. 
[8] D. Mosca Angelucci, V. Stazi, A.J. Daugulis, M.C. Tomei, Treatment of synthetic tannery wastewater in a continuous two-phase partitioning bioreactor: Biodegradation of the organic fraction and chromium separation, Journal of Cleaner Production. 152 (2017) 321-329. https://doi.org/10.1016/j.jclepro.2017.03.135.

[9] D. Baskaran, T. Paul, P. Kannan, M. Krithivasan, D. M.g., R. Rajamanickam, Batch degradation of trichloroethylene using oleaginous Rhodococcus opacus in a two-phase partitioning bioreactor and kinetic study, Bioresource Technology Reports. 11 (2020) 100437. https://doi.org/10.1016/j.biteb.2020.100437.

[10] A.J. Daugulis, Two-phase partitioning bioreactors: a new technology platform for destroying xenobiotics, Trends in Biotechnology. 19 (2001) 457-462. https://doi.org/10.1016/S01677799(01)01789-9.

[11] B. Mahanty, K. Pakshirajan, V. Venkata Dasu, Biodegradation of pyrene by Mycobacterium frederiksbergense in a two-phase partitioning bioreactor system, Bioresource Technology. 99 (2008) 2694-2698. https://doi.org/10.1016/j.biortech.2007.05.042.

[12] R. Muñoz, S. Arriaga, S. Hernández, B. Guieysse, S. Revah, Enhanced hexane biodegradation in a two phase partitioning bioreactor: Overcoming pollutant transport limitations, Process Biochemistry. 41 (2006) 1614-1619. https://doi.org/10.1016/j.procbio.2006.03.007.

[13] G. Darracq, A. Couvert, C. Couriol, A. Amrane, P. Le Cloirec, Removal of Hydrophobic Volatile Organic Compounds in an Integrated Process Coupling Absorption and BiodegradationSelection of an Organic Liquid Phase, Water Air Soil Pollut. 223 (2012) 4969-4997. https://doi.org/10.1007/s11270-012-1251-0.

[14] G. Darracq, A. Couvert, C. Couriol, D. Thomas, A. Amrane, E. Dumont, Y. Andres, P. Le Cloirec, Optimization of the volume fraction of the NAPL, silicone oil, and biodegradation kinetics of toluene and DMDS in a TPPB, International Biodeterioration \& Biodegradation. 71 (2012) 9-14. https://doi.org/10.1016/j.ibiod.2012.03.004.

[15] G. Quijano, M. Hernandez, F. Thalasso, R. Muñoz, S. Villaverde, Two-phase partitioning bioreactors in environmental biotechnology, Appl Microbiol Biotechnol. 84 (2009) 829-846. https://doi.org/10.1007/s00253-009-2158-6.

[16] E. Dumont, H. Delmas, Mass transfer enhancement of gas absorption in oil-in-water systems: a review, Chemical Engineering and Processing: Process Intensification. 42 (2003) 419-438. https://doi.org/10.1016/S0255-2701(02)00067-3.

[17] R. Muñoz, S. Villaverde, B. Guieysse, S. Revah, Two-phase partitioning bioreactors for treatment of volatile organic compounds, Biotechnology Advances. 25 (2007) 410-422. https://doi.org/10.1016/j.biotechadv.2007.03.005.

[18] M.T. Cesário, W.A. Beverloo, J. Tramper, H.H. Beeftink, Enhancement of gas-liquid mass transfer rate of apolar pollutants in the biological waste gas treatment by a dispersed organic solvent, Enzyme and Microbial Technology. 21 (1997) 578-588. https://doi.org/10.1016/S01410229(97)00069-0.

[19] L. Bailón, M. Nikolausz, M. Kästner, M.C. Veiga, C. Kennes, Removal of dichloromethane from waste gases in one- and two-liquid-phase stirred tank bioreactors and biotrickling filters, Water Research. 43 (2009) 11-20. https://doi.org/10.1016/j.watres.2008.09.031.

[20] E. Dumont, Y. Andrès, P. Le Cloirec, Effect of organic solvents on oxygen mass transfer in multiphase systems: Application to bioreactors in environmental protection, Biochemical Engineering Journal. 30 (2006) 245-252. https://doi.org/10.1016/j.bej.2006.05.003.

[21] S. Cantera, J.M. Estrada, R. Lebrero, P.A. García-Encina, R. Muñoz, Comparative performance evaluation of conventional and two-phase hydrophobic stirred tank reactors for methane abatement: Mass transfer and biological considerations, Biotechnology and Bioengineering. 113 (2016) 1203-1212. https://doi.org/10.1002/bit.25897.

[22] R. Muñoz, A.J. Daugulis, M. Hernández, G. Quijano, Recent advances in two-phase partitioning bioreactors for the treatment of volatile organic compounds, Biotechnology Advances. 30 (2012) 1707-1720. https://doi.org/10.1016/j.biotechadv.2012.08.009.

[23] A.D. Dorado, E. Dumont, R. Muñoz, G. Quijano, A novel mathematical approach for the understanding and optimization of two-phase partitioning bioreactors devoted to air pollution control, Chemical Engineering Journal. 263 (2015) 239-248. https://doi.org/10.1016/j.cej.2014.11.014.

[24] D.R. Nielsen, A.J. Daugulis, P.J. McLellan, Dynamic simulation of benzene vapor treatment by a two-phase partitioning bioscrubber: Part I: Model development, parameter estimation, and parametric sensitivity, Biochemical Engineering Journal. 36 (2007) 239-249. https://doi.org/10.1016/j.bej.2007.02.026. 
[25] M.H. Fazaelipoor, A model for treating polluted air streams in a continuous two liquid phase stirred tank bioreactor, Journal of Hazardous Materials. 148 (2007) 453-458. https://doi.org/10.1016/j.jhazmat.2007.02.060.

[26] M. Hernández, R. Muñoz, A.J. Daugulis, Biodegradation of VOC mixtures of different hydrophobicities in two-phase partitioning bioreactors containing tailored polymer mixtures, Journal of Chemical Technology \& Biotechnology. 86 (2011) 138-144. https://doi.org/10.1002/jctb.2496.

[27] G. Darracq, Couplage de l'absorption dans une phase organique et de la biodégradation dans un réacteur multiphasique. Application au traitement de Composés Organiques Volatils hydrophobes, These de doctorat, École nationale supérieure de chimie de Rennes, 2011.

[28] M. Guillerm, Optimisation du couplage de l'absorption et de la biodégradation pour l'élimination de Composés Organiques Volatils hydrophobes, These de doctorat, Ecole nationale supérieure de chimie de Rennes, 2017.

[29] A.S. Rodriguez Castillo, Conception, caractérisation et mise en oeuvre de Liquides loniques au sein d'un procédé couplant absorption et biodégradation pour le traitement de COV hydrophobes, These de doctorat, École nationale supérieure de chimie (Rennes), 2016.

[30] G. Darracq, A. Couvert, C. Couriol, E. Dumont, A. Amrane, P. Le Cloirec, Activated Sludge Acclimation for Hydrophobic VOC Removal in a Two-Phase Partitioning Reactor, Water Air Soil Pollut. 223 (2012) 3117-3124. https://doi.org/10.1007/s11270-012-1094-8.

[31] D.R. Nielsen, A.J. Daugulis, P.J. McLellan, Dynamic simulation of benzene vapor treatment by a two-phase partitioning bioscrubber: Part II: Model calibration, validation, and predictions, Biochemical Engineering Journal. 36 (2007) 250-261. https://doi.org/10.1016/j.bej.2007.02.027.

[32] J.V. Littlejohns, K.B. McAuley, A.J. Daugulis, Model for a solid-liquid airlift two-phase partitioning bioscrubber for the treatment of BTEX, Journal of Chemical Technology \& Biotechnology. 85 (2010) 173-184. https://doi.org/10.1002/jctb.2280.

[33] P. Pré, Y. Andrès, C. Gérente, P. Le Cloirec, Procédés : mise en œuvre et applications, Techniques de l'Ingénieur. 1 (2004).

[34] J.E. Bailey, D.F. Ollis, Biochemical Engineering Fundamentals, McGraw-Hill, 1986.

[35] H. Yoon, G. Klinzing, H.W. Blanch, Competition for mixed substrates by microbial populations, Biotechnology and Bioengineering. 19 (1977) 1193-1210. https://doi.org/10.1002/bit.260190809.

[36] J. Villadsen, J. Nielsen, G. Lidén, Bioreaction Engineering Principles, 3rd ed., Springer US, 2011.

[37] M. Roustan, Absorption en traitement d'air, Techniques de l'Ingénieur. 1 (2004).

[38] M. Lhuissier, A. Couvert, A. Amrane, A. Kane, J.-L. Audic, Characterization and selection of waste oils for the absorption and biodegradation of VOC of different hydrophobicities, Chemical Engineering Research and Design. 138 (2018) 482-489. https://doi.org/10.1016/j.cherd.2018.08.028.

[39] L.J. Thibodeaux, D. Mackay, Handbook of Chemical Mass Transport in the Environment, CRC Press, Boca Raton, 2010.

[40] P. Turq, J.-P. Simonin, Mesure des coefficients de diffusion, Techniques de l'Ingénieur. (1990).

[41] M.B. Shiflett, A. Yokozeki, Solubilities and Diffusivities of Carbon Dioxide in lonic Liquids: [bmim][PF6] and [bmim][BF4], Ind. Eng. Chem. Res. 44 (2005) 4453-4464. https://doi.org/10.1021/ie058003d.

[42] A. Yokozeki, Time-dependent behavior of gas absorption in lubricant oil, International Journal of Refrigeration. 25 (2002) 695-704. https://doi.org/10.1016/S0140-7007(01)00066-4.

[43] A. Datta, L. Philip, S. Murty Bhallamudi, Modeling the biodegradation kinetics of aromatic and aliphatic volatile pollutant mixture in liquid phase, Chemical Engineering Journal. 241 (2014) 288-300. https://doi.org/10.1016/j.cej.2013.10.039.

[44] D.W. Ostendorf, T.H. Schoenberg, E.S. Hinlein, S.C. Long, Monod Kinetics for Aerobic Biodegradation of Petroleum Hydrocarbons in Unsaturated Soil Microcosms, Environ. Sci. Technol. 7 (2007) 2343-2349. https://doi.org/10.1021/es062313l.

[45] D. Frascari, D. Pinelli, M. Nocentini, E. Baleani, M. Cappelletti, S. Fedi, A kinetic study of chlorinated solvent cometabolic biodegradation by propane-grown Rhodococcus sp. PB1, Biochemical Engineering Journal. 42 (2008) 139-147. https://doi.org/10.1016/j.bej.2008.06.011.

[46] P. Balasubramanian, L. Philip, S.M. Bhallamudi, Biodegradation of Chlorinated and Nonchlorinated VOCs from Pharmaceutical Industries, Appl Biochem Biotechnol. 163 (2011) 497518. https://doi.org/10.1007/s12010-010-9057-2.

[47] D. Quesnel, G. Nakhla, Removal kinetics of acetone and MIBK from a complex industrial wastewater by an acclimatized activated sludge, Journal of Hazardous Materials. 132 (2006) 253-260. https://doi.org/10.1016/j.jhazmat.2005.09.048. 
[48] M.H. El-Naas, J.A. Acio, A.E. El Telib, Aerobic biodegradation of BTEX: Progresses and Prospects, Journal of Environmental Chemical Engineering. 2 (2014) 1104-1122. https://doi.org/10.1016/j.jece.2014.04.009.

[49] M. Lhuissier, A. Couvert, A. Kane, A. Amrane, J.-L. Audic, P.-F. Biard, Experimental evaluation and modeling of the hydrodynamics in structured packing operated with viscous waste oils, Chemical Engineering Research and Design. 162 (2020) 273-283. https://doi.org/10.1016/j.cherd.2020.07.031.

[50] R. Lebrero, D.F. Osvaldo, V. Pérez, S. Cantera, J.M. Estrada, R. Muñoz, Chapter Seven Biological treatment of gas pollutants in partitioning bioreactors, in: S. Huerta-Ochoa, C.O. Castillo-Araiza, G. Quijano (Eds.), Advances in Chemical Engineering, Academic Press, 2019: pp. 239-274. https://doi.org/10.1016/bs.ache.2018.12.003.

[51] A. Krishnamurthy, B. Adebayo, T. Gelles, A. Rownaghi, F. Rezaei, Abatement of gaseous volatile organic compounds: A process perspective, Catalysis Today. 350 (2020) 100-119. https://doi.org/10.1016/j.cattod.2019.05.069.

[52] W.L. McCabe, J.C. Smith, P. Harriott, Unit Operations of Chemical Engineering, McGraw-Hill, 1993.

\section{Chemical Engineering Journal}

Highlights

- The modeling of the biodegradation of 7 VOCs in a pilot-scale TPPB is presented

- Model is validated by comparison to experimental data with toluene only and the 7 VOCs

- Modeled results reveal 3 groups of molecules reacting differently to biodegradation

- Model shows that " $\mathrm{k} \mathrm{a}$ " is a key parameter to enhance NAPL biological regeneration

- The developed model shows that modelling results are closed to experimental results 